\title{
Correction to: Drug Delivery from an Innovative LAMA/LABA Co-suspension Delivery Technology Fixed-Dose Combination MDI: Evidence of Consistency, Robustness, and Reliability
}

\author{
Amber Doty, ${ }^{1}$ Jon Schroeder, ${ }^{2}$ Kou Vang, ${ }^{1}$ Mark Sommerville, ${ }^{1}$ Mervin Taylor, ${ }^{1}$ Brad Flynn, ${ }^{1}$ \\ David Lechuga-Ballesteros, ${ }^{2}$ and Peter Mack ${ }^{1,3}$
}

\section{Correction to: AAPS PharmSciTech}

https://doi.org/10.1208/s12249-017-0891-1

This article was originally published Online First without open access. After publication it was discovered that the author had ordered open access during the production process. The incorrect license was assigned to this paper due to a technical error. Therefore, the copyright of the article has been changed to The Author(s) 2017 and the article is forthwith distributed under the terms of the Creative Commons Attribution. The original article was corrected.

Open Access This article is distributed under the terms of the Creative Commons Attribution 4.0 International License (http://creativecommons.org/licenses/by/4.0/), which permits unrestricted use, distribution, and reproduction in any medium, provided you give appropriate credit to the original author(s) and the source, provide a link to the Creative Commons license, and indicate if changes were made.

The online version of the original article can be found at https:// doi.org/10.1208/s12249-017-0891-1.

\footnotetext{
${ }^{1}$ Pearl Therapeutics Inc., 4222 Emperor Blvd, Suite 560, Durham, North Carolina, 27703, USA.

${ }^{2}$ Pearl Therapeutics Inc., Redwood City, California, USA.

${ }^{3}$ To whom correspondence should be addressed. (e-mail: peter.mack@astrazeneca.com)
} 